\title{
CONVERSA, PARTILHA E FORMAÇÃO DOCENTE: 0 FÓRUM DE ALFABETIZAÇÃO, LEITURA E ESCRITA (FALE)
}

\author{
Tiago Ribeiro (INES)* \\ Carmen Sanches Sampaio (PPGEdu/UNIRIO)**
}

\section{RESUMO}

0 presente ensaio é desdobramento de uma pesquisa de doutorado defendida em 2019, cujo objetivo foi pensar acerca do processo de alfabetização de crianças a partir de narrativas de docentes alfabetizadores. As narrativas, fruto de encontros do Fórum de Alfabetização, Leitura e Escrita da Universidade Federal do Estado do Rio de Janeiro (UNIRIO), bem como a própria proposta de fórum, dão a ver, além de questões ligadas à alfabetização, modos outros de pensar, praticar e viver o processo formativo. 0 texto centra-se nesta dimensão, convidando a pensar sobre uma formação que se dá na relação com o outro, através da partilha e do conversar como possibilidade transformativa. Defende o formativo como lugar de encontro, descoberta, estranhamento e transformação, dialogando com narrativas de algumas professoras alfabetizadoras participantes da pesquisa.

Palavras-chave: Formação docente. Conversação. Experiência. Singularidade.

\section{ABSTRACT}

\section{CONVERSATION, SHARING AND TEACHER TRAINING: THE LITERACY, READING AND WRITING FORUM (FALE)}

This essay is the result of a doctoral research defended in 2019, whose objective was to think about the literacy process of children from narratives of literacy teachers. The narratives, the result of meetings of the Universidade Federal do Estado do Rio de Janeiro (UNIRIO) Literacy, Reading and Writing Forum, as well as the forum proposal itself, show, besides issues related to literacy, other ways of thinking, practicing and living the teachers training process. The text

\footnotetext{
Doutor em Educação pela Universidade Federal do Estado do Rio de Janeiro (UNIRIO). Professor e Orientador Pedagógico dos Anos Iniciais do Ensino Fundamental noturno do Instituto Nacional de Educação de Surdos (INES). Cocoordenador do Grupo de Pesquisa ArteGestoAção do Instituto Nacional de Educação de Surdos (INES) e integrante do Grupo de Pesquisa Práticas Educativas e Fromação de Professores da Universidade Federal do Estado do Rio de Janeiro (GPPF/ UNIRIO) e da Rede de Formação Docente: narrativas e experiências (Rede Formad/Brasil). E-mail: tribeiro.ines@gmail.com.

** Pós-doutorado em Educação pela Universidad de Buenos Aires e Flacso. Professora Associada da Escola de Educação e do Programa de Pós-Graduação em Educação da Universidade Federal do Estado do Rio de Janeiro (PPGEdu/UNIRIO). Cocoordenadora do Grupo de Pesquisa Práticas Educativas e Formação de Professores (GPPF/UNIRIO). Coordenadora da Rede de Formação Docente: narrativas e experiências (Rede Formad/Brasil). E-mail: carmensanches.unirio@gmail.com.
} 
focuses on this dimension, inviting us to think about a teachers training that takes place in the relationship with the other, through sharing and talking as a transformative possibility. It defends the formative as a place of encounter, discovery, strangeness and transformation, dialoguing with narratives of some literacy teachers participating in the research.

Keywords: Teacher training. Conversation. Experience. Singularity.

\section{RESUMEN}

\section{CONVERSACIÓN, INTERCAMBIO Y FORMACIÓN DOCENTE: EL FORO DE ALFABETIZACIÓN, LECTURA Y ESCRITURA (FALE)}

Este ensayo se desarrolla a partir de una investigación doctoral defendida en 2019, cuyo objetivo era pensar en el proceso de alfabetización de niños a partir de narrativas de alfabetizadores. Las narraciones, resultado de las reuniones del Foro de Alfabetización, Lectura y Escritura de Universidade Federal do Estado do Rio de Janeiro (UNIRIO), así como la propuesta del foro en sí, muestran, además de temas relacionados con la alfabetización, otras formas de pensar, practicar y vivir el proceso formativo. El texto se enfoca en esta dimensión, invitándonos a pensar en una formación de maestros que se lleva a cabo en la relación con el otro, a través de compartir y hablar como una posibilidad transformadora. Defiende lo formativo como un lugar de encuentro, descubrimiento, extrañeza y transformación, dialogando con las narrativas de algunas maestras alfabetizadoras que han participado en la investigación.

Palabras clave: Formación docente. Conversación. Experiencia. Singularidad.

\section{Introdução ${ }^{1}$}

Há alguns anos, em um livro publicado em um dos colóquios sobre Educação e Filosofia ocorridos na Universidade do Estado do Rio de Janeiro (UERJ), organizado pelo Núcleo de Educação, Filosofia e Infância (NEFI), descobrimos Giorgio Agamben, filósofo italiano contemporâneo cuja produção discute uma gama variada de questões: economia, soberania, direito, entre outros temas. Agamben (2013) lançou, em um cenário de suposto êxito social do capitalismo frente ao esgarçamento, à derrocada dos sonhos e esperanças de uma comunidade outra, à luz das experiências políticas de tal sorte na Europa, seu livro A comunidade que vem. Nele, tece uma reflexão distinta das até então disponíveis, deslocando a comunidade

1 A pesquisa que dá origem a este texto seguiu as recomendações e procedimentos éticos de investigação. Os nomes utilizados nas narrativas são verdadeiros, com autorização prévia dos participantes. do lugar do "comunitarismo" e pensando o sujeito como alguém que, escapando à comunidade enquanto classe de idênticos, ratifica sua singularidade irrepetível.

Assim, a comunidade que vem, em Agamben (2013), não é a sociedade dos mesmos, idênticos, dos transformados em um conjunto. Tampouco é a sociedade - ou a comunidade - do futuro. Ela é profanação e é agora; não se deixa programar, não se deixa angariar. Que vem, neste sentido, é o que está sempre chegando (ANTELO, 2013), se construindo, se fazendo e refazendo; é o que desloca as coisas um pouquinho do lugar. Que vem é o que profana o estar e o ser, o lugar e o tempo. Estilhaça as identidades enquanto essência ou matriz sólida - não existe o é, somente o sendo: na comunidade que vem não há essência, pois esta é gerúndio. 0 que há é o qualquer, este que se singulariza e, sendo 
singular, não obedece a manuais, sumários ou compêndios.

O sujeito não é um espelho que reflete a diferença, uma diferença ou algumas diferenças próprias da "diversidade". Ora, inexiste diferença fora da relação entre pessoas singulares e irrepetíveis. A diferença é entre. Assim, a comunidade que vem é complexidade pura: está e não está, virá e não virá; é contemporânea. Ela é justamente o ponto de inflexão que impossibilita a completude; abre a própria comunidade à transformação, porque se manter como comunidade que vem é também manter-se em aberto, ao lado (isto é, com um espaço ao lado para que outras existências se façam presentes em seu ser qualquer), resistindo ao sujeito que aí está como parte do coletivo enquanto "conjunto". E essa resistência à ideia de "classe" (enquanto conjunto) se dá pela impossibilidade de aceitação de quaisquer confrarias que possam apagar o rosto, o nome singular de cada sujeito em prol de uma comunidade sob a insígnia de uma identidade comum compartilhada. Não existe um singular edificante do Uno, mas um singular-plural, aquele que ratifica a diferença enquanto relação e aponta, em seu âmago, à multiplicidade, ao qualquer.

No encontro com Giorgio Agamben, tonificou-se o convite a voltarmos ao experienciado no Fórum de Alfabetização, Leitura e Escrita (FALE), criado como um projeto de pesquisa e extensão com o objetivo maior de investir no diálogo e na troca entre universidade e escola básica, tendo como nutriente da conversação experiências e acontecimentos vividos por docentes, nos cotidianos das escolas. Voltamos a trabalhar com o corpus dessa pesquisa referente ao FALE no bojo da ação investigativa de doutoramento de Tiago Ribeiro: Por uma alfabetizacão sem cartilha: narrativas e experiências compartilhadas no Fórum de Alfabetizacão, Leitura e Escrita da UNIRIO (RIBEIRO, 2019), defendida em fevereiro de 2019, sob orientação de Carmen Sanches Sampaio e coorientação do Prof. Dr. Carlos Skliar (FLACSO/Argentina), com o desafio de pensar uma alfabetização as- sente na construção compartilhada e coletiva de sentidos, na conversação, na curiosidade, no desejo e na descoberta como dimensões constitutivas do aprender e ensinar a ler e a escrever.

Com Agamben, nos situamos ao lado do sujeito qualquer, corroborando, neste sentido, a negação da existência de uma essência sacralizante. Reclamamos pelo sujeito singular, de carne, osso e desejos, ou seja, o sujeito da formação, porque em constante transformação. Este que está aqui e agora, em sua existência corporal e afetiva, cuja materialidade nos interpela, nos provoca, nos convida, nos atrai. E em que medida a materialidade das narrativas docentes partilhadas no FALE nos interpelam, provocam, convidam, atraem?

Neste texto, pensamos/conversamos a respeito da formação docente a partir do vivido no FALE, dando a ver algumas ideias e sentidos que têm nos provocado a refletir, na direção de uma ideia outra acerca da formação de professorxs. ${ }^{2}$ Temos, no grupo de que participamos na universidade, pensado e praticado a formação docente referendada pelos princípios da alteridade, do cuidado, da atenção, da conversa, da experiência e do trabalho em redes como formas alternativas para a organização e a formação do trabalho docente, no exercício cotidiano de vivenciar a trans-formação/invenção de si como processo conversacional. Trata-se, portanto, de que a lógica da explicação possa ceder lugar à lógica da conversação, de modo que o saber possa ser abordado como um instrumento capaz de empoderar os que carecem de poder (FALS BORDA, 2010), sem produzir, no processo, novas relações de sulbaternizacão.

2 A escrita da marca de gênero com o x é uma opção cada vez mais presente em textos acadêmicos, sobretudo no campo dos estudos com os cotidianos. Essa opção busca questionar uma lógica binária segundo a qual somente dois gêneros são possíveis: masculino e feminino, denotando machismo e misoginia, uma vez que o masculino prevalece sobre o feminino e outras expressões de gênero são invisibilizadas. Como não há uma "gramática" do uso do " $x$ " (nem a queremos!), além do desafio desse tipo de escrita, acabamos decidindo por alternar o uso do x. Ela aparece em palavras aleatórias, com o sentido de produzir desconforto e atenção para o tema. 
Opções teórico-epistemológicas, éticas, metodológicas e políticas que reclamam por compreensões outras, além de linguagens e outros marcos de pensamento, numa perspectiva de descolonialidade e libertação (DUSSEL, 2011; FANON, 2015; FREIRE, 2005; HOOKS, 2013; KRENAK, 2019).

Afinal, pergunta-nos, com insistência, Spivack (2010): "pode o sulbaterno falar"? E, a partir de sua pergunta, perguntamos: podem xs professorxs falar? Quais professorxs podem falar? Como falam? Quando falam? Falam? Podem xs professorxs escrever? Pesquisar? Publicar o que escrevem? Como? Onde? Quando? Por quê? E, mais ainda, são xs docentes outros legítimos da formação? Seus saberes, experiências e vozes importam?

\section{Fórum de Alfabetização, Leitura e Escrita}

O Fórum de Alfabetização, Leitura e Escrita (FALE), espaço formativo privilegiado neste texto, aconteceu pela primeira vez no dia três de março de 2007, com o tema "Leitura, Alfabetização: tudo a ver", na Universidade Federal do Estado do Rio de Janeiro (UNIRIO). Os encontros eram parte do projeto de pesquisa e extensão intitulado Fórum Estadual de Alfabetização: discutindo, investigando $e$ implementando políticas e práticas de leitura e escrita (SAMPAIO, 2007a).

Esse é o primeiro encontro do FALE (Fórum de Alfabetização Leitura e Escrita) - um projeto financiado com o apoio da FAPERJ. Qual é o objetivo do FALE? Que a gente se encontre uma vez por mês para conversar sobre as práticas e concepções cotidianas. Qual é o objetivo maior? Articular prática-teoria-prática. Que consigamos viver aqui, neste 'espaçotempo', durante nove encontros, essa circularidade de, a partir da prática, teorizar sobre ela e voltar à prática. Para quê? Essa é a pergunta... Para retornar à prática compreendendo-a de modos outros, ampliando nossas possibilidades de pensar e atuar. (SAMPAIO, 2007b).

Dos nove encontros previstos para aconte- cer ao longo do ano de 2007, ${ }^{3}$ período no qual ocorreria o projeto, o FALE se espichou. Entre os anos de 2007 e 2013 aconteceram 40 encontros - todos filmados e transcritos - mediante a importância que tal ação foi ganhando junto a professorxs da escola básica, que garantiam um público médio de 200 pessoas por encontro. Compete lembrar que, focando sempre na discussão da prática alfabetizadora vivida no cotidiano escolar, o FALE passou a acontecer, também, em outras cidades fluminenses além do Rio de Janeiro: em 2009 e 2014 aconteceu em Três Rios e Angra dos Reis, respectivamente. Além dessas duas cidades, onde os encontros aconteceram ao longo de um ano, por meio de uma parceria com as Secretarias de Educação, o FALE acontece, atualmente, na Faculdade de Formação de Professores da Universidade do Estado do Rio de Janeiro (FFP/UERJ), em São Gonçalo (RJ), coordenado pelas professoras Jacqueline de Fátima dos Santos Morais ${ }^{4}$ e Mairce Araújo; na UNICAMP, em Campinas (SP), com a coordenação do professor Guilherme do Val Toledo Prado e, desde março de 2018, na Universidade Federal do Pará (UFPA), em Belém (PA), coordenado pela professora Elizabeth Orofino.

Todos os encontros, indiferentemente da cidade onde acontecem ou tenham acontecido, perseguem um princípio comum: a conversa (RIBEIRO; SOUZA; SAMPAIO, 2018) como meio para o pensar com o outro e como potência para a transformação. Puxam essa conversa sujeitos encarnadxs, gente de carne e osso que vivencia e constrói o cotidiano da alfabetização,

3 Projeto financiado pela Fundação de Amparo à Pesquisa do Estado do Rio de Janeiro (FAPERJ), em seu primeiro ano- 2007.

4 A professora e amiga Jacqueline de Fátima, sempre presente na criação e fortalecimento da Rede Formad, nos deixou, fisicamente, no dia 12 de outubro de 2019. Continua, entretanto, presente em sua ausência, em nossas ações e processos experienciados na perspectiva das redes de formação docente. Suas ideias, apostas, produção teórica, sempre à pràtica articulada, acompanha-nos através de seus livros, artigos e textos e, sobretudo, pelo tanto que nos habita como companheira de luta cotidiana por uma escola e universidade públicas populares e por um país democrático e com justiça social. 
na escola e/ou na universidade. ${ }^{5}$ Assim, as mesas do FALE são compostas por, ao menos, umx docente da universidade e umx docente da escola básica. ${ }^{6}$ Ambos falam de suas experiências e práticas no campo da educação; de suas práticas, pesquisas e aprendizagens. A palavra circula, ganha diferentes ecos e tonalidades; não pertence à mesa, a umx ou a outrx; é de todxs. Todxs podem falar, expor seu ponto de vista, perguntar, comentar, interpelar.

Após as narrativas dxs docentes que puxam a conversa, a plateia é convidada a se colocar, deixar suas marcas, seus rastros. Quiçá o mais bonito neste movimento é que, pela proposta mesma do FALE, o objetivo dos encontros se distancia da ideia de alcançar ou oferecer respostas e/ou de ratificar métodos, metodologias ou sequências didáticas - essas que já habitam aos montes as páginas dos manuais e livros didáticos. 0 que se pretende, isso sim, é provocar o pensamento, insistir na indagação, convidando a modificarmos um pouco, aqui e ali, nossos modos de compreender o ensinar a ler e a escrever, abrindo espaço para a indagação de si, em um movimento onde a fala não pode ser compreendida sem aquilo que, na sua relação com ela, torna possível a conversa: a escuta.

Nós pensamos em trabalhar alfabetização, leitura e escrita pensando no próprio título do fórum também como uma palavra e não apenas como sigla. Ele é importante como sigla, mas é fundamental como palavra. Porque falar é falar com; falar para é uma doença, é um equívoco, pois não leva em conta o outro como interlocutor. No nosso cotidiano nós falamos com; a gente fala com o outro e expõe. 0 ato de interlocução pressupõe a troca de papéis; uma hora você fala, outra hora você ouve. Dizem até que nós temos dois ouvidos e uma boca que é para ouvir mais, mas nós somos pessoas que falamos muito. [...] o FALE, FALE, FALE... Está pressuposto que é o

5 Durante o texto utilizamos tempos verbais no presente e/ou no passado ao nos referirirmos ao FALE, pois temos FALEs já finalizados e outros em andamento.

6 No total, apresentaram-se no FALE/UNIRIO 30 professorxs alfabetizadorxs ligadxs à escola básica e 20 professorxs ligadxs à universidade. Cinco dos encontros não contaram com a participação de professorxs da Universidade na composição da mesa.
FALE criança, FALE colega, FALE[m] todos. Falemos todos uns com os outros porque somente assim que a fala tem sentido. (ZACCUR, 2007).

Seguindo essa circularidade do falar e do pensar evocada na narrativa da professora Edwiges, em que o falar emerge, também, como lugar de escuta, o FALE não quer encerrar um conceito de alfabetização nem o delimitar, não quer traçar receitas nem ensinar a alfabetizar, tampouco almeja ensinar a ensinar. 0 desafio é distanciar-se de um manual ou de um desejo de dizer a outro o que e/ou como fazer, de traçar quaisquer caminhos. 0 que pulsa, o que dá vida ao Fórum é o desejo de ir ao encontro daquilo que segue no silêncio, na clandestinidade das salas de aula, no anonimato das práticas: modos e maneiras (LARROSA, 2018) de ser professorx alfabetizadorx através de conversas com e entre docentes, ouvir sobre as sutis e potentes histórias de quem vive e conta o cotidiano escolar, de quem o cria e inventa diariamente com estudantes.

Quanta riqueza, beleza, esperança, conhecimentos e histórias são produzidas diariamente no chão da escola? Quantos saberes circulam aí, renovando e transformando o já sabido, o já pensado? Quantos detalhes, por mínimos que sejam, potenciam a escola no seu estar sendo, apontando para horizontes de possibilidades ao fazer escolas na escola? (KOHAN, 2013). E por que não serem vistos e reconhecidos esses modos de fazer escola, de inventar a relação e o educativo com o outro, na própria escola? Por que grande parte das políticas e práticas de formação desvaloriza e ignora tais poéticas e produções? É possível abrir espaço para que, em vez de pretensamente ensinar, possamos aprender juntxs escutando, estando presentes e nos aproximando de tantas histórias singulares e pessoais dos e nos cotidianos escolares?

Estar presente, falar, compartilhar, ouvir, pensar juntxs... A potência talvez esteja na circulação da palavra, no gesto, na interrogação. Talvez esteja nesse movimento de inquietação permanente, de desconfiança que acompanha o processo de formação-investigação (e inves- 
tigação-formação) enquanto transformação um percurso autoral, singular e coletivo. Talvez esteja nos silêncios que nos separam e nos velam, nas palavras silenciadas, nas palavras mal digeridas, nos incômodos gerados.

Por isso, algo de contemporâneo no FALE... Porque é uma forma de suspender o próprio tempo e o espaço da formação: não é agora, nem antes nem depois; não é aqui nem ali; é na relação, no encontro/confronto entre sujeitos quaisquer e toda a contingência que daí flui, sujeitos singulares que se dão a ver na relação, que se tecem e entretecem no corpo a corpo, se fazem na e por meio da língua(gem) e da interlocução/interação (BAKHTIN, 2011). A formação não acontece em um espaço determinado, em um tempo delimitado; ela é vivida entre, na distância que nos une e separa, naquilo que não podemos prever nem controlar, dada sua dimensão acontecimental.

Desse modo, o FALE insere ou coloca um pequeno graveto nas engrenagens das políticas formativas vigentes; emperra a maquinaria do "atualizar/capacitar" outrem, deixando as coisas como estão, mas já diferentes: inexatamente iguais! Mais do que respostas, investe na escuta; escuta como lugar de aprendizado, de (trans)formação, de conversa. E porque contemporâneo, na sua desimportância tão importante, profana o tempo, quebra a cronologia, plasma outros tempos; tempos outros para a formação, pois este (o tempo da formação) não é identificável por qualquer cronômetro ou relógio nem simultâneo; trata-se de um tempo singular, da intensidade, aiônico.

0 tempo da formação resiste à dança das horas, desobedece à linearidade do tempo cronológico, entrelaça presente e passado. É a impossibilidade de um tempo esquadrinhado no tempo, uma explosão, estilhaços de tempo, vórtices, espichamentos, espaçamentos, persistências, resistências, intensidades, emaranhados. Multiplicidades e singularidades. Um tempo que repercute, ressoa, toca.

Às vezes ouvimos algo, mas não podemos escutar. As palavras não nos dizem nada nem nos alcançam ou tocam, não produzem sentido ou efeito. E isto porque o tempo da formação não é literal, melhor dizendo, não é concomitante nem antecipável. 0 formativo não é uma seta de alguém em direção a outro, tampouco um processo alheio a quem o vive. Cada umx experiencia sua formação como um percurso único, irrepetível, pessoal, ainda que habitado por tantas outras existências. Carlos Skliar, em conversa com Carmen Sanches Sampaio e Maria Teresa Esteban, nos adverte:

[...] a formação é feita de encontros e desencontros, e não necessariamente de decisões pessoais ou de uma tomada de consciência, de repente. Relaciona-se com tudo isso. Muitas pessoas podem te falar ao ouvido da importância da leitura, a importância da escrita, mas, na verdade, tem um momento em que isso precisa acontecer contigo mesmo. Um momento em que você sente: 'Eu já sei que é importante, mas hoje eu descobri esse fato no meu corpo.' É como o amor, quando as pessoas dizem 'o amor é importante, não dá para viver sem'. Mas as pessoas têm de descobrir esse momento para elas - 0 amor. Ainda que a experiência do amor seja universal e se repita ao longo da história, é só nesse momento, que não é uma novidade no sentido moderno da palavra, mas é a primeira vez. Acho que muito da educação relaciona-se com essa 'primeira vez'. Esse momento no qual o aluno, o outro, descobre, pela vez primeira, uma coisa que tem sido repetida já muitas vezes. (SAMPAIO; ESTEBAN, 2012, p. 314-315).

E formar-se, aprender é, de algum modo, sentir pela primeira vez, ainda que esta primeira vez seja a repetição feita diferença, a repetição que se modifica na irrepetibilidade do instante: acontecimento. Vemos mil vezes uma imagem, lemos duas mil vezes um texto, mas o tremor, o arrepio, a falta de palavras, o sentir-se emudecidx, a ardência no corpo, a experiência, o dar-se conta que também é uma dimensão do formativo (SKLIAR, 2017), a impossibilidade de manter-se exatamente tal qual se é... Todas essas sensações e sentimentos não são necessariamente simultâneos. Em outras palavras, repetimos mais uma vez: a formação não acontece no mesmo instante em que 
vemos, lemos, ouvimos ou vivemos algo. Não é um ponto nem uma reta, não é um resultado nem uma ação; ela é processo, fluxo, rizoma, emaranhado, caos. Às vezes precisamos deixar que o que nos chega ressoe em nós, repercuta silenciosamente até que possamos, de alguma maneira, sentir/pensar o que não cessa de fazer-se intuição, percepção, incômodo.

Isso de olhar para o como deixamos de ser aquilo que éramos não encontramos numa história arrumada, nas linearidades evolutivas nem nas cartilhas explicativas e/ou expositivas de uma vida. Isso se encontra na vida mesma: na impossibilidade de controle, na incerteza do próximo passo, nos encontros e desencontros, nos horrores perante o mundo, no assombro, na utopia, no desejo, nas conversações, nas paixões e esperanças, nas situações degradantes, na despedida, na perda, nas injustiças, nos livros que lemos e não lemos, nos textos que nos marcaram, nos textos que não pudemos escrever senão de forma caótica, não linear, naqueles outros sobre os quais tanto ouvimos e nunca pudemos ler, nas poesias ouvidas, lidas ou escritas, nas artes que nos afetam, nos lugares que visitamos ou não pudemos fazê-lo, nas amizades que tecemos etc. Isto, há muito, nos inspira a pensar Michel Foucault (2006), sobretudo quando nos fala da vida como invenção, criação, e da formação como um processo de artesania e cuidado de si. Formar-se é, como o amor e a amizade, matéria de relação, cuidado e atenção, porque sem relação - com x outro, com o mundo e consigo mesmx - tampouco sabemos quem somos.

Contudo, falar do FALE é mais do que pensar nesse tempo da formação. É também tocar suavemente as bordas, as fronteiras, o que aproxima a própria ideia de formação da de pesquisa, como dissemos anteriormente, com a proposição de uma investigação-formação. Está em jogo, cremos, uma formação e uma pesquisa que sejam experiência: que possam atravessar, marcar, afetar, transformar o sujeito. Um processo cujo desenvolvimento e vivência não deixem quem a experiencia exatamente igual a quando começou a se aventurar nessa viagem.

Quiçá estejamos falando de uma maneira de pesquisar/formar-se que não se sustenta fora da assinatura em primeira pessoa, com a presença e a ausência dx próprix autorx, mas que essas presença e ausência sejam de certo modo também marca de sua forma singular de se colocar ou não se colocar, de falar em sua língua ou silenciar.

O FALE faz parte da nossa formação e, portanto, de nossa própria história como professorxs-pesquisadorxs. Investigar narrativas docentes produzidas durante seus encontros, narrativas de experiências partilhadas por professorxs que buscam modos outros de aprender/ensinar a ler e a escrever é, também, investigar narrativas que nos forma(ra)m, que soam e ressoam em nós, que vão produzindo territórios possíveis onde pensar a formação para além da ideia e desejo de explicação/ criticização do outro.

Entretanto, é preciso alguma dose de advertência, de cuidado, de atenção. Uma formação em primeira pessoa, com assinatura e nome próprios, isto é, uma formação na qual estamos nós, com nossas experiências, biografias, dúvidas, anseios e fragilidades precisa de face, cheiro, presença. E isso talvez não se alcance sob a égide das bíblias das sagradas escrituras didáticas ou dos sermões acadêmicos do formativo. Precisamos tomar alguma distância, semear perguntas.

Se o acontecimento não pode ser provocado, mas é aquilo que vem sorrateiro, suspende o tempo e interrompe o fluxo das horas e, como nos fala Derrida (2012), cai no colo, enquanto acontecimento, poderíamos pensar se a formação pode ser provocada ou garantida: o FALE, nesse sentido, forma ou abre espaço para uma conversação na qual podemos viver encontros, desencontros, estranhamentos e deslocamentos?

Ao investir na formação na perspectiva do acontecimento e não na da capacitação e/ou atualização, o FALE consubstancia-se como 
um convite a que nos coloquemos ex-postos diante do outro, de sua fala, de sua narrativa. Que escutemos (ou tentemos escutar, o que se faz com uma certa dose de silêncio, de calar-se para ouvir outrem) essx outro em sua língua, por mais que ela não nos seja compreensível ou traduzível, com toda a dificuldade (ou impossibilidade) que isso implica. Como $x$ outro me atravessa? Como me afeta? Que ressonâncias sua fala/língua/presença me provoca? Que gestos comparte?

Colocar-se exposto significa, entre outras coisas, não dissociar o pesquisar do formar nem o formar do pesquisar (não pesquisar $\mathrm{x}$ outro, mas - e sobretudo - a si mesmx nesse exercício narrativo, a partir das provocações, dos conselhos (BENJAMIN, 1994) que a experiência, a narrativa do outro comporta ou pode comportar).

Enquanto espaçotempo de encontros, compartilhas e ex-posição, o FALE reclama pelo reconhecimento do vivido e do experienciado como nutriente formativo. Tal golpe vislumbra a possibilidade de afastamento do totalitarismo das ações e currículos de formação impostos de cima para baixo, arbitrária e inflexivelmente. Igualmente, reclama por uma política formativa que não transforme $\mathrm{x}$ outro em sujeito inanimadx, meramente passivx, receptáculo vazio, destituídx de vida, história, experiência. Os sujeitos que o compõem, por meio de suas narrativas, ativam a potência do encontro e dão a ver, quiçá, um cotidiano que sobrevive às imposições políticas que, cotidianamente, são apresentadas como o caminho a ser seguido.

Trata-se de um modo outro de compreender e viver a formação, pautando-a em princípios que vão ao encontro do desejo da tessitura de um mundo outro, de relações outras, orientado pelas ideias de colaboração, solidariedade, horizontalidade e amizade; uma formação pensada fora da tônica mercadológica do produzir, reproduzir, consumir... Uma proposição que corrói, portanto, as engrenagens mais tilintantes da subjetividade capitalística.
Por ser - ou ao menos buscar ser em sua complexidade - uma ação que interrompe o habitual e o esperado, o FALE corrobora o pensamento enquanto forma de indisciplina (LARROSA, 2014). Uma indisciplina desconstrutiva, derridiana, aquela que obedece desobedecendo, porque não é subversão, mas ação, afirmação! Desloca um milímetro, um centímetro, um decímetro, porque sabe que o movimento e a transformação são, como o oxigênio, necessários à vida e à fragilidade humanas.

\section{Sobre presença e atenção: formar-se como possibilidade de (des)encontro com o outro}

Educar, provoca Skliar (2017), e, dizemos nós: formar-se tem a ver com sentir com $\mathrm{x}$ outro, padecer, alegrar-se, comover-se. Importa mais a educação que vem, para usar a ideia do que vem agambeniana - como aquilo que insere uma pausa no estar sendo e abre o mundo em outros possíveis. Educação e formação que vem como uma educação e formação que sejam, elas mesmas, rebeldia, desobediência, inquietação. Educar (e formar-se) para transgredir (HOOKS, 2013).

E seguir afirmando a educação e a formação como atos políticos, transgressores, no sentido da radical assunção de que não se trata de dar a voz, mas de ouvi-la, tomá-la, assumi-la (SKLIAR, 2017), é imprescindível... Ora, trata-se de uma coerência ética e político-investigativo-metodológica como um posicionamento no mundo que compreende $x$ outrx como alguém que tem algo a dizer, a ensinar, como tantas vozes tem nos ensinado, em diferentes áreas e campos do conhecimento. Todxs e qualquer umx são alguém que, porque vivem, têm história, trajetória, têm o que dizer, criam e inventam modos de existência. Rancière (2011) nos ajuda neste sentido, pois nos provoca a pensar o processo de assunção de si e dx outro enquanto potência afirmativa como um movimento descolonial, 
sublinhamos nós, sobre o ser e o pensar, o viver e o fazer: um ato educativo desembrutecedor que escapa à necessidade de ratificação de supostas desigualdades intelectuais. Isto é: perceber a si e a outrem como sujeitos de fala, história, pensamento, saber é um ato afirmativo ética e politicamente comprometido.

Um ato afirmativo ética e politicamente comprometido com o fato de que todos e qualquer um é sujeito legítimo na/da formação (RIBEIRO; SOUZA; GUEDES, 2018), que são sujeitos que inventam e constroem caminhos. Nesse cenário, pensar uma possibilidade de formação outra vai ao encontro da compreensão da alteridade como a expressão afirmativa de um self, da necessidade menos de explicação, de definição, mas de atenção. Quiçá viver o formativo tenha a ver, a partir desse lugar, com prestar atenção, o que nos demanda rever nossas próprias palavras e verdades, nossas próprias crenças e linguagens, de se abrir aos acontecimentos, achados, silêncios e assombros que a experiência partilhada, escrita, narrada, desenhada pode promover.

Os processos formativos, nesse sentido, são espaçostempos de invenção, criação, partilhas, lugar de e para pensar com x outro, conversar, colocar em questão nossas verdades, perceber o que sozinhxs talvez não pudéssemos perceber ou pensar. Assim, a aposta inalienável nos sujeitos cotidianos como autorxs dos processos vividos, na escola como lugar de invenção (ALVES, 2008)! Uma resposta, portanto, aos nossos modos aprendidos e apreendidos de pensar a formação no contexto da escola e com seus sujeitos, bem como a relação desta com o conhecimento e com a universidade (SÜSSEKIND; GARCIA, 2011): trata-se de conversar, de aprender e ensinar, de compartilhar e pôr em movimento saberes e práticas, experiências e ideias!

Dessa maneira, o FALE, como tantas outras experiências instituintes de formação (SAMPAIO; RIBEIRO; MORAIS, 2014), é uma alternativa possível a modos hegemônicos e colonizadores de pensar, pesquisar e produzir conhecimento sobre a escola e sobre histórias da escola; modos que, historicamente, sublinham suas faltas, suas carências e invisibilizam suas potências (SAMPAIO, 2010).

As narrativas docentes partilhadas no FALE dão a ver um movimento de formação não como aplicação, aquisição ou iluminação, porém como um elemento criativo que não antecede a invenção (construção) do próprio percurso. Formação como processo criativo e investigativo e formativo e e e...! Quiçá, mais do que explicação, capacitação ou atualização, a formação tenha a ver com atenção, escuta, cuidado, presença, encontro com o outro.

Em outras palavras, poderíamos pensar que se formar é da ordem da experiência. Se aceitamos que a experiência é aquilo que passa, que atravessa e modifica o sujeito (LARROSA, 2014), então a experiência da formação - enquanto viagem, invenção/composição de si também - tem a ver com o acontecer, a travessia, a transformação, os encontros. Aqui ressoa, insistimos em sublinhar mais uma vez, um modo de viver e estar no formativo que se relaciona com a educação, a investigação e o próprio sujeito. Dizendo em outras palavras, de viver e pensar o formar-se a partir de ideias como presença, atenção, inquietação do pensamento.

\section{Quando falam as professoras (ou sobre encontros, formação, alfabetização e fazer-se outro de si)}

No mergulho nas transcrições das narrativas compartilhadas nos encontros do FALE/ UNIRIO, ao passo que vamos lendo mais e mais narrativas e, juntamente com elas, as conversas tecidas após as apresentações, uma questão principal vai ganhando forma, pois é repetida muitas vezes, em diferentes encontros, por diferentes participantes: "Como começar [a alfabetizar]?", "Como trabalhar desde o início sem cartilha?", "0 que fazer antes de os alunos 
lerem e escreverem?"... perguntas presentes em diferentes encontros do FALE/UNIRIO. Perguntas que já nos fizemos, com insistência, como professorxs alfabetizadorxs. Lembro-me que não compreendia o que Regina Leite Garcia ${ }^{7}$ me sinalizava com o seu olhar e silêncio mediante a "grande mudança" que acreditávamos viver, à época, na escola: a mudança do método de alfabetização.

O olhar e o silêncio de Regina me inquietaram. Lembro-me de algumas perguntas que iam e vinham depois daquele encontro: o que Regina deixou de me dizer? Por que não me disse o que parecia sinalizar? Será que mudar de um método para o outro significa mesmo uma mudança? O que muda? 0 que não muda? A partir do encontro, instigada pelo gesto de Regina, passei e passamos, professorxs de cujo grupo eu fazia parte, a estudar, na escola, os métodos de alfabetização que conhecíamos: seus princípios teórico-práticos, políticos e metodológicos. E, nesse movimento, fui e fomos, na escola, compreendendo o defendido por Paulo Freire (2005) e Regina Leite Garcia (2015) desde sempre: a potência da prática. (SAMPAIO; VENÂNCIO; RIBEIRO, 2019, p. 69).

No FALE/UNIRIO, diferentes professorxs narraram suas práticas em sala de aula tendo esta questão - como alfabetizar sem cartilha - como foco de suas narrativas. Em um desses encontros, duas professoras a narrarem suas práticas foram Ana Paula Venâncio - professora, mulher, negra, atuante no movimento negro e comprometida com a construção de uma alfabetização antirracista que afirma as diferenças, as singularidades e pode ser lugar de viver outras relações - e Margarida dos Santos - mulher, mãe e professora negra que vem apostando na potência do encontro com $\mathrm{x}$ outro para fazer do educativo espaçotempo de pluralização de destinos, isto é, espaçotempo de viver relações éticas de alteridade. Elas narram:

Ser professora é um processo de construção, com

7 Coordenadora, no período de 1988 a 2016, do Grupo de Pesquisa Alfabetização dos Alunos e Alunas das Classes Populares (GRUPALFA), um grupo interinstitucional com a participação de professorxs vinculadxs à UNIRIO, Universidade Federal Fluminense (UFF) e UERJ/São Gonçalo, sediado na Faculdade de Educação da UFF. certeza. Por que é um processo de construção? Porque, quando eu iniciei, quando era criança, eu tinha um desejo. A escola era o desejo... E depois esse desejo de escola se transformou em algo muito ruim; [...] Depois que terminei minha vida escolar e fui fazer o Normal, fui trabalhar em escola, eu percebi que eu repetia aquilo com os alunos, o que me faziam lá atrás: a ordem, a repetição. Na escola particular eu colocava as crianças umas atrás das outras, eu mandava copiar sem saber o porquê, eu mandava cumprir o programa sem discutir. Estou reproduzindo aquilo que aprendi na vida, na minha formação e até mesmo na escola Normal, porque não teve muita mudança. (VENÂNCIO, 2007).

[...] Então a questão que queria trazer de volta aqui é que esse incômodo, a minha preocupação de catar, de desconfiar que crianças sabiam coisas sobre leitura e escrita, que elas... Não era verdade que elas não queriam nada, que nós precisávamos pensar... e tentar fazer o que nós ainda não sabíamos na prática com elas. Isso nem sempre foi assim. Nem sempre me preocupei com isso. Eu comecei quase 10 anos depois de formada com essa preocupação. Essa preocupação, ela vai nascendo do que vou observando nas escolas e dos encontros e diálogos que vou podendo tecer com pessoas que já pensavam diferente de mim e espaços onde eu tinha oportunidade de discutir teoricamente, e a prática que me incomodava, que começava a incomodar no contato com esses alunos. (SANTOS, 2007).

Ana Paula e Margarida também são filhas das classes populares e trazem em suas histórias as marcas de uma sociedade racista, preconceituosa, desigual e que destina axs pobres e negrxs um futuro discursiva e materialmente construído e constituído pela falta, pela negação, pela subalternização e pela exploração. Suas histórias, nossas histórias, se repetem no cotidiano das escolas, nos corpos e vidas das crianças, dxs estudantes e nas relações que tecemos ( $\mathrm{e}$ às vezes travamos, no sentido mais literal do verbo) com elxs. Relações, muitas vezes, nas quais $\mathrm{x}$ outro não é vistx em sua potencialidade, em sua alteridade irrepetível, em sua potência, em sua igualdade (RANCIÈRE, 2011), mas como umx incapaz, alguém cujo destino já vem estampado e decidido pela crueza de uma "realidade" imposta ou prevista: "É 
pobre, preto, favelado, vai querer mais o quê?" - perguntam despudoradamente algumxs.

Todavia, as narrativas de Ana Paula e Margarida partilhadas no FALE nos ensinam que nossas vidas e histórias também são textos que vamos compondo e, como todo texto, atravessam-lhes outros textos, outras vidas e histórias; são polifônicas! Vão acontecendo no encontro, no estar juntxs, no fazer e pensar coisas juntxs. Inexiste - insistimos e repetimos - eu sem x outro, de modo que a narração de nossos percursos formativos são também a narrativa de uma trajetória habitada e atravessada por pessoas, lugares, literaturas, livros, filmes, músicas, textos etc. que diferem e põem em xeque nossas paisagens mentais, ideias, crenças, valores, nossos territórios e cartografias epistêmicas, afetivas etc. Sem esta tensão que viver nas diferenças nos impõe, não chegamos a ser quem somos, tampouco podemos diferir de nós mesmxs e devir outrxs de nós:

Bom, e aí, como pode? Já ia me incomodando, mas eu não tinha um parceiro com quem conversar, com quem expor. Eu não tinha ninguém que me dissesse: "vamos pensar de outro jeito? Vamos trabalhar de outro jeito?". As colegas com as quais eu trabalhava na escola particular e no CIEP eram professoras que também viveram o mesmo processo e aprenderam da mesma forma. Então, eu não tinha como desviar muito disso. Quando eu tive a minha primeira filha, entrei em um concurso de remoção e entrei para o Instituto de Educação e deixei o CIEP, que era muito longe da minha casa. Fui para o Instituto de Educação por uma questão de localidade. Chegando ao Instituto, eu encontrei um trabalho muito interessante na alfabetização e professoras muito interessantes também. Encontrei a professora Jacqueline, que tinha sido minha professora no adicional e já tinha mexido comigo antes do Instituto. E encontrei no Instituto a professora Margarida, que foi a primeira pessoa com quem tive contato direto e rápido. Ela trabalhava com alfabetização. Nós começamos a conversar no primeiro dia e foi me questionando e me fazendo cada pergunta... Eu ficava me perguntando por que ela fazia perguntas: 'Mas por que você trabalha assim?', 'Você já trabalhou desse jeito?', 'Já trabalhou assim?' No primeiro dia em que eu peguei a turma, ela começou a me perguntar, e eu fui ficando incomodada e aí eu fui encontrando outras pessoas que foram me [ajudando] a pensar. (VENÂNCIO, 2007).

[...] Especialmente no trabalho com esses alunos... [estigmatizadxs pela escola como incapazes, repetentes, candidatxs ao 'fracasso escolar'] Comecei o trabalho com esses alunos e, sobretudo, vou aprendendo com eles porque me desafiavam. Eu já era alfabetizadora há 10 anos e tinha um montão de crenças, especialmente as contribuições do construtivismo, da psicogênese da língua escrita. Então, no início da década de 90 [1990], [isso] me fez mudar muito o meu modo de alfabetizar. Comecei a creditar que crianças possuíam saberes sim, crianças levantavam hipóteses sim, mas sobretudo os saberes... [...] Ora, estava trabalhando com uma galera de 12,13, 14, 15, 16, 17 anos, um grupo de alunos que estavam desacreditados e não conseguiam enxergar a escola como um lugar que os acolhesse e acreditasse nas suas capacidades. Foram estigmatizados durante muito tempo na turma especial. E aí ousei fazer isso. Quando resolvi fazer isso, foi assim: o caos retornou, a coisa se complicou, eles não queriam me ouvir, eles não queriam participar mais dos encontros, eles não queriam saber! E o problema que começava a se confirmar, no modo como olhava e trabalhava com essas crianças, o discurso das minhas colegas e meus em alguns momentos de que as crianças não queriam nada... Então, num dado momento, eu comecei [a me desafiar] muito instigada pela leitura de um livro de uma autora chamada Ana Luiza Smolka, em que ela convida a gente para um outro olhar em relação às práticas da leitura e escrita dentro da sala de aula. (SANTOS, 2007).

Sim, as narrativas nos ensinam: ser é sendo; formar-se é formando-se; um horizonte sempre um pouco mais além cujo percurso não podemos fazer sem x outro, sem a presença incômoda e indigesta da alteridade radical, daquelxs que destoam de nós em demasia, daqueles corpos com os quais não sabemos interagir, em relação aos quais não temos repertórios nem experiências prévias, que nos emudecem, põem em dúvida ou fazem ruir em pedaços nossas convicções: a formação não é algo solitário nem uma ação individual; tem um quê de pessoal, singular, único. Entretanto esta irrepetibilidade tem a ver com o modo como outras existências 
e presenças nos habitam, nos ferem, nos tombam, nos fazem aflorar angústias, inseguranças, desencontros, estranhamentos, dúvidas, desejos, inquietudes, potências, nos lembra Carlos Skliar (2017).

Nesse movimento, devimos outrxs, vamos em busca do que sequer sabemos o que é, nos (re)construímos nessa relação/tensão que a alteridade nos brinda. Nisso investe a ideia de formação como conversação: que possamos estar presentes na relação, na conversa, colocar nossas vozes, corpos e miradas. Por que não? Há quem pode falar e quem não pode? Há quem mereça falar e quem não? Por quê? 0 que acontece quando nos desafiamos a viver a formação em rodas de conversação?

Ao potencializarmo-nos no encontro com o outro, podemos rever não apenas quem somos, porém nossas práticas e modos de viver e enxergar o educativo? Tornarmo-nos docentes outrxs? Por isso a formação como convite ao pensamento, ao estar juntxs, ao deslocamento de nossas ideias e verdades, a que possamos colocar na roda nossas vivências e experiências, aprender e ensinar no narrar e no escutar, ao ouvir e ver também a prática de outrxs docentes, seus sucessos e tropeços. Esta era e é a aposta do FALE. Nos encontros, docentes apresentam suas práticas e, então, conversase. Colocam-se corpos, vozes, presenças, biografias... E do que se trata o formar-se senão disso, desse movimento do qual não saímos exatamente do modo como entramos, desse espaço onde podemos, no coletivo, no encontro/ confronto com o outro, ampliar modos de ver, saber, se emocionar, padecer, sentir?

Érika Vargas, também professora alfabetizadora comprometida com o processo de criação e de autoria das crianças, atuante na rede municipal de uma cidade do centro-sul fluminense, reforça, em sua narrativa produzida no FALE, assim como Ana Paula Venâncio, a ideia de que o outro que nos interpela pode fazer-se presente de muitos modos, seja de sua presença física, de sua produção intelectual etc.: uma teoria, um texto, uma conversa, um relato. 0 que nos narra Érika lembra-nos da ideia de personagens conceituais, de Deleuze e Guattari (2010). Tais personagens apresentam a força de "manifestar territórios, desterritorializações e reterritorializações absolutas do pensamento" (DELEUZE; GUATTARI, 2010, p. 84): personagem conceitual é aquilo que abre nosso pensamento ao múltiplo, à diferença, convoca a pensar, mas não existe senão na relação que tecemos com o mundo, com x outro, com isto que, não sendo nós, também nos forma e transborda. É acontecendo, pensando.

[...] Eu já estou no meu 11ㅇan ano dentro de uma sala de aula, com alfabetização. Eu tenho certeza de que ainda estou engatinhando nesse processo, não sei tudo. [...] Quando eu iniciei a minha primeira turma foi de C.A., quando me formei. No início, eu tinha muitas incertezas, muitas dúvidas de como fazer. Alfabetizei os meus primeiros alunos utilizando os métodos tradicionais, de silabação, fônicos, mas também não me sentia segura... Eu não dava condições aos meus alunos de terem autonomia. Então, eu também me questionava muito. E hoje, assim, o pró- letramento [programa de formação do governo federal para docentes alfabetizadores] me ajudou muito nessa questão de como ver os meus alunos, de como planejar as aulas. Hoje eu junto a teoria à prática. Eu não consigo mais ter uma prática onde eu não tenha estudo, onde eu não tenha alguma reflexão [...] (VARGAS, 2011).

Perguntei para as crianças sobre o que gostariam de fazer. Entre as respostas, algumas disseram que gostariam de fazer dever e aprender a ler e escrever. Mas brincar foi a atividade mais citada. Continuei instigando e perguntando: - De qual brincadeira?

- Pique-alto, pique-esconde, pique-banco, futebol, pique-cola e boneca - disseram as crianças. Foi feita uma votação para a escolha da brincadeira daquele dia e pedi que o aluno Juan registrasse em nosso blocão o nome da brincadeira, quando falou:

- Mas eu não sei escrever...

- Nós vamos te ajudar! Olha as letras do alfabeto! - disse Camilla.

Era o primeiro dia de aula com aquelas crianças. Para a maioria daqueles alunos e alunas, a escola não é lugar de brincar. Na sala de aula, a ansie- 
dade para usar os cadernos, lápis e a borracha chega a gerar certa angústia se não são logo utilizados. Juan foi surpreendido pela proposta da escrita. De certa forma, naquele momento, percebeu que a escrita iria exigir mais do que até aquele momento fizera. Porém, se encorajou a escrever quando Camilla, aluna alfabetizada, disse: 'Nós vamos te ajudar, olha as letras do alfabeto!'

O alfabeto colocado junto ao quadro não se tornaria uma sequência de letras mortas, estando ali somente para enfeitar a sala. Era a ele que Juan deveria recorrer para escrever o nome da brincadeira. Camilla chama a atenção para as letras, solicita que as consulte para escrever o nome da brincadeira. Juan, ao escrever, foi sendo ajudado pelas outras crianças, que informavam a letra, levantavam hipóteses de escrita, gritavam para ele uma letra, outros diziam que não era aquela; ou seja, um ambiente de muito barulho e troca de saberes. As dúvidas se tornavam discussões. Os alunos com 'um pouco mais de conhecimento' sobre a língua ajudavam e formulavam hipóteses. Sem muita interferência da professora, a palavra pique-alto foi escrita no blocão. (VENÂNCIO, 2009).

As narrativas compartilhadas no FALE descortinam movimentos transformativos docentes que miram, perseguem modos outros de ensinar e aprender a ler e a escrever; modos comprometidos com a invenção, a autoria, a produção, a articulação com a vida, o mundo, o fazer e pensar coisas juntos. Ademais, dão a ver uma dimensão colaborativa e coletiva do processo singular formativo de cada pessoa. Somos, estamos sendo e vamos fazendo-nos outros de nós na relação com outros.

Sim, obviamente formar-se é de ordem pessoal, tem a ver com um caminho singularmente percorrido, mas qualquer protagonismo, em se tratando de formação, é um protagonismo compartilhado, exercido no coletivo, nas redes de formação e colaboração que vamos tecendo! (ALVES, 2008). 0 aprender (o formar-se), como a vida, é feito de atividade e passividade; é social. 0 que está em jogo é uma passividade disponível, aberta: "Passividade feita de paixão, de padecimento, de paciência, de atenção" (LARROSA, 2014, p. 25).
Dessa forma, ler e escrever, como um processo também de formação em que as crianças vão se tornando outras de si mesmas e sendo interpeladas - e interpelando-se - através da escrita, têm a ver com o que apaixona, machuca, provoca, afasta e desperta. Não têm a ver somente com uma função social ou com uma utilidade prática; têm a ver também com o que segue inexpresso até que explode, com o que irrompe e rasga: antes de sermos seres de ação, somos seres de paixão, de linguagem, de relação, embora sejam estas dimensões também presentes na ação.

Então, mais uma vez: como começar se somos seres de atividade passiva e passividade ativa? Esse "como" no início da pergunta, embora possa em alguns contextos imprimir um sentido de "receita", não delimita nem define um caminho único. Existem sempre mil e um modos de se lançar em um sendeiro, em uma trajetória; incontáveis formas de criar uma rota própria. E esta rota diz respeito à maneira como a construímos enquanto a vamos vivendo, compondo com outrxs nossas maneiras e modos de ser, estar e fazer (LARROSA, 2018). Diz respeito não necessariamente a uma ação ou um modo de agir, mas a uma dis-posição, a uma ex-posição, a um jeito de mirar o outro em sua alteridade, nessa relação de e na diferença.

No e com o FALE, (re)lendo de novo e uma vez mais as transcrições, vamos dando-nos conta da dimensão experiencial do FALE. Uma formação-experiência, para nós, que abre possibilidades de formar(-nos) cotidianamente no próprio processo de formação docente. Professorxs da universidade não fala(va)m para professorxs da escola básica nem viceversa; fala(va)m umxs com outrxs; aprendiam e aprendem, ensinavam e ensinam juntxs, em relação, através do exercício desafiador de conversar e, nesse conversar, o compartilhar entre diferentes vozes que, coletivamente, se pensam, se estranham, concordam, discordam, interrogam modos de pensar e de fazer nos cotidianos das escolas, dando-se e não se dando conta... Contudo, não é através da 
conversa, deste falar inconcluso e em aberto, acontecimental, que nos tornamos sujeitos narrativxs, de língua(gem), de e em formação, de conversação?

\section{Palavras finais para ensaiar novas conversações}

Conversação, conversas inconclusas... Neste ponto talvez esteja a dimensão mais contemporânea do FALE, enquanto projeto ou proposta de formação que vem, se entendemos "que vem" agambenianamente como o que está sendo, fazendo-se, aqui e agora, na relação. Somos muitxs, cada umx de nosso modo singular de ser. Diferença. Diferenças.

Diferenças de tempos, lugares, histórias que se contemporaneizam na copresença, isto é, inexiste o "à frente do tempo". Estamos todxs neste tempo plural no qual vamos nos formando, tal qual nos ensina a perspectiva histórico-cultural: nos tornamos sujeitos com $\mathrm{x}$ outro, através das interações, partilhas, redes e conversações tecidas/vividas. Na perspectiva agambeniana (AGAMBEN, 2014), contemporâneo não tem a ver com a idade atual ou com o tempo presente. Contemporâneo é o que mantém as coisas inexatamente iguais, que as rasga com suas perguntas, suas ações, por miúdas e mínimas que sejam. Delx é a percepção de finitude de seu próprio tempo, esse tempo tão marcado por luzes e trevas; dele é a coragem de não coadunar milimetricamente com um mundo e um tempo que se apresentam tempestivos.

Em tempos onde estão em alta políticas de formação que buscam capacitar e atualizar professorxs, compreendendo-xs como incapazxs e/ou desatualizadxs (SAMPAIO; RIBEIRO; MORAIS, 2014); em tempos nos quais secretárixs de educação afirmam sua preocupação com a "aplicação" de técnicas e metodologias de ensino e subestimam a importância do pensar, do refletir e do criar, ações e práticas de formação que reconhecem e investem em saberes e fazeres docentes são, em alguma medida, contemporâneas. Contemporâneas porque nos apresentam imagens outras da escola, porque nos mostram outras histórias, experiências e ações, porque alargam nossos mapas cognitivos e afetivos acerca do educativo e não corroboram as verdades definitivas, investindo em outras políticas de (re)conhecimento docente e de seu fazer na produção de uma narrativa outra sobre o aprender/ensinar a ler e a escrever - a partir da escola, em sua pulsação viva, em seu caráter formativo e não dogmático, como provocam Masschelein e Simmons (2014).

Nesse sentido, o FALE soa e ressoa, para nós, como um projeto que guarda algo de contemporâneo, pois, diante dos ditames da “capacitação para aplicação", diante da supremacia da necessidade das "metodologias estruturadas", investe na partilha, na narrativa, no intercâmbio de experiências pedagógicas, no dar-se tempo para ouvir e para se ouvir, para pensar, para sentir. Abre um pequeno espaço no fluxo habitual das políticas formativas e muda os termos da conversação: não se fala para, mas com. Pensa-se com. Conversa-se. Conversamos.

O FALE nos ensina que o tempo da formação é um tempo outro. Longe das métricas, dos sistemas de medida, padronizações, linearidades... Algo mais como um tempo de interrupção, profano, imensurável: "é um limiar inapreensível entre um 'ainda não' e um 'não mais'” (AGAMBEN, 2014, p. 29, grifo do autor). Portanto, um tempo que se espicha e perdura, tempo presente, de presença, atenção, escuta, espera e de uma certa forma de cuidado com o mundo, com os outros e com nós mesmos (LARROSA, 2008). Tempo que se pluraliza e complexifica não se deixando reduzir a um tempo único. Um tempo feito de tempos, de singularidades pulsantes.

O tempo da formação se arrasta, esgueirase, intumesce e persiste; é o tempo que vem. Borra os contornos tão bem definidos do tempo cronológico, um tempo demarcado e demarcável. Isto porque, enquanto acontecimento, imprevisibilidade e contingência, a formação, 
enquanto experiência, se situa em uma temporalidade outra. Quiçá seu tempo seja uma sorte de tempos que se tocam, transformam-se e confundem-se. Tempo paradoxal, da intensidade, do encontro, da ruminação de ideias, palavras e imagens. Nele, a experiência passada se faz presença, se reconfigura no presente e se lança e/ou persiste no futuro que, no entanto, é devir... Afinal, para “'darmo-nos conta', necessitamos de tempo, espaço, solidão [...] Aprender é 'dar-se conta', sim" (SKLIAR, 2019, p. 46-47). Formar-se, igualmente, é ir dando-nos conta do mundo ao longo de nossa travessia no mundo.

Talvez, nos processos de formação docente, dar(-se) tempo para a chegada do mundo, para a chegada do outro e para a chegada de nós mesmos, como insiste Jorge Larrosa (2008), seja o que de mais valioso possamos oferecer(nos). E a esta pergunta o FALE nos convida: que mundos temos conhecido nesse mundo que se pluraliza em milhões? Que experiências, vozes, narrativas temos conhecido, escutado, sentido?

\section{REFERÊNCIAS}

AGAMBEn, G. A comunidade que vem. Belo Horizonte: Autêntica, 2013.

AGAMBEN, G. Nudez. Belo Horizonte: Autêntica, 2014.

ALVES, N. Decifrando o pergaminho: o cotidiano das escolas nas lógicas das redes cotidianas. In: OLIVEIRA, I. B.; ALVES, N. (org.). Pesquisa nos/ dos/com os cotidianos das escolas: sobre redes de saberes. 3. ed. Rio de Janeiro: DP\&A, 2008. p. 15-38.

ANTELO, R. Apresentação. In: AGAMBEN, Giorgio. A comunidade que vem. Belo Horizonte: Autêntica, 2013. p. 3-4.

BAKHTIN, M. Estética da criação verbal. 6. ed. São Paulo: Martins Fontes, 2011.

BENJAMIN, W. Magia e técnica, arte e política: ensaios sobre literatura e história da cultura. São Paulo: Brasiliense, 1994.

DELEUZE, G.; GUATTARI, F. o que é filosofia? São Paulo: Editora 34, 2010.

DERRIDA, J. Uma certa possibilidade impossível de dizer o acontecimento. Revista Cerrados, v. 21, n.
33, p. 231-251, 2012.

DUSSEL, E. Filosofia de la liberación. México: FCE, 2011.

FALS BORDA, O. Pesquisa-ação, ciência e educação popular nos anos 90. In: STRECK, D. (org.). Fontes da pedagogia latino-americana: uma antologia. Belo Horizonte: Autêntica, 2010. p. 358-370.

FANON, F. Los condenados de la tierra. Buenos Aires: Fondo de Cultura Económica, 2015.

FOUCAULT, M. Ditos e escritos III. 2. ed. Rio de Janeiro: Forense Universitária, 2006.

FREIRE, P. Pedagogia do oprimido. 48. Reimpressão. Rio de Janeiro: Paz e Terra, 2005.

HOOKS, B. Ensinando a transgredir: a educação como prática da liberdade. São Paulo: Martins Fontes, 2013.

KOHAN, W. O. 0 mestre inventor: relatos de um viajante educador. Belo Horizonte: Autêntica, 2013.

KRENAK, A. Ideias para adiar o fim do mundo. São Paulo: Companhia das Letras, 2019.

LARROSA, J. Esperando não se sabe o quê: sobre o ofício de professor. Belo Horizonte: Autêntica, 2018.

LARROSA, J. Tremores: escritos sobre experiência. Belo Horizonte: Autêntica, 2014.

MASSCHELEIN, J.; SIMONS, M. A pedagogia, a democracia, a escola. Belo Horizonte: Autêntica, 2014.

RANCIÉRE, J. 0 mestre ignorante: cinco lições sobre a emancipação intelectual. 3. ed. Belo Horizonte: Autêntica, 2011.

RIBEIRO, T. Por uma alfabetização sem cartilha: narrativas e experiências compartilhadas no fórum de alfabetização, leitura e escrita da UNIRIO. 2019. 195f. Tese (Doutorado em Educação) - Programa de Pós-Graduação em Educação, Universidade do Estado do Rio de Janeiro (UNIRIO), Rio de Janeiro, 2019.

RIBEIRO, T.; SOUZA, R.; GUEDES, A. O. Infância, alteridade e formação docente: encontro com as crianças como potência de transformação. Childhood \& Philosophy, Rio de Janeiro, v. 14, n. 30, p. 261-276, maio/ago. 2018.

RIBEIRO, T.; SOUZA, R.; SAMPAIO, C. S. (org.). Conversa como metodologia de pesquisa: por que não? Rio de Janeiro: Ayvu, 2018.

SAMPAIO, C. S. Fórum estadual de alfabetização: discutindo, investigando e implementando políticas 
e práticas de leitura e escrita. Projeto de Pesquisa. Rio de Janeiro: FAPERJ, 2007a.

SAMPAIO, C. S. Abertura. In: FÓRUM DE ALFABETIZAÇÃO, LEITURA E ESCRITA, 1., 2007, Rio de Janeiro. Anais [...]. Rio de Janeiro: UNIRIO, 2007b.

SAMPAIO, C. S. Redes coletivas de (auto)formação docente: narrativas, experiências e a (re)construção de saberes e fazeres alfabetizadores. In: MORAES, D. Z; LUGLI, R. S. (org.). Docência, pesquisa e aprendizagem: (auto)biográficas como espaços de formação/investigação. São Paulo: Cultura Acadêmica, 2010. p. 129-145.

SAMPAIO, C. S.; ESTEBAN, M. T. Conversa com Carlos Skliar... provocações para pensar em uma educação outra. Revista Teias, v. 13, p. 269-283, 2012.

SAMPAIO, C. S.; RIBEIRO, T; MORAIS, J. Fá. S. Formação docente instituinte: o Fórum de Alfabetização, Leitura e Escrita. Revista Aleph, v. 11, n. 22, p. 114-127, 2014.

SAMPAIO, C. S.; VENÂNCIO, A. P.; RIBEIRO, T. Alfabetização sem cartilha (ou sobre autoria, escuta e atenção no aprender/ensinar a ler e a escrever. In: SAMPAIO, C. S.; LACERDA, M. P.; RIBEIRO, T. (org.). Alfabetizacão sem cartilha: gestos, experiências e narrativas. Rio de Janeiro: Ayvu, 2019. p. 63-97.

SANTOS, M. C. Alfabetização: diferentes lógicas no ensinar e no aprender. In: FÓRUM DE ALFABETIZAÇÃO, LEITURA E ESCRITA, 5., 2007, Rio de Janeiro. Anais [...]. Rio de Janeiro: UNIRIO, 2007. SKLIAR, C. A escuta das diferenças. Porto Alegre: Mediação, 2019.

SKLIAR, C. Pedagogías de las diferencias: notas, fragmentos, incertidumbres. 4. reimpressão. Buenos Aires: Noveduc, 2017.

SPIVACK, G. C. Pode o subalterno falar? Belo Horizonte: Editora UFMG, 2010.

SÜSSEKIND, M. L.; GARCIA, A. Universidade-escola: diálogo e formação de professores. Rio de Janeiro: FAPERJ, 2011.

VARGAS, E. Alfabetização, avaliação e heterogeneidade: diferentes modos de aprender (e ensinar). In: FÓRUM DE ALFABETIZAÇÃO, LEITURA E ESCRITA, 31., 2011, Rio de Janeiro. Anais [...]. Rio de Janeiro: UNIRIO, 2011.

VENÂNCIO, A. P. Leitura e alfabetização: tudo a ver. In: FÓRUM DE ALFABETIZAÇÃO, LEITURA E ESCRITA, 1., 2007, Rio de Janeiro. Anais [...]. Rio de Janeiro: UNIRIO, 2007.

VENÂNCIO, A. P. Alfabetização sem cartilha? Por onde começar? In: FÓRUM DE ALFABETIZAÇÃO, LEITURA E ESCRITA, 17., 2009, Rio de Janeiro. Anais [...]. Rio de Janeiro: UNIRIO, 2009.

ZACCUR, E. Leitura e alfabetização: tudo a ver. In: FÓRUM DE ALFABETIZAÇÃO, LEITURA E ESCRITA, 1, 2007, Rio de Janeiro. Anais [...]. Rio de Janeiro: UNIRIO, 2007. 